\title{
The Review of the Implicit Followership Theories (IFTs)
}

\author{
Shulan Guo \\ Jinan University, Guangzhou, China \\ Email: 13424060860@136.com
}

How to cite this paper: Guo, S. L. (2018). The Review of the Implicit Followership Theories (IFTs). Psychology, 9, 623-632. https://doi.org/10.4236/psych.2018.94039

Received: March 5, 2018

Accepted: April 10, 2018

Published: April 13, 2018

Copyright $\odot 2018$ by author and Scientific Research Publishing Inc. This work is licensed under the Creative Commons Attribution International License (CC BY 4.0).

http://creativecommons.org/licenses/by/4.0/

\begin{abstract}
Implicit followership Theories (IFTs) are defined as cognitive structures and schemas about the traits and behaviors that characterize followers. Goals of this research were to: 1) identify the content of IFTs; 2) analyze the structure of IFTs; 3) explain the research status of Implicit Followership Theories. Implicit Followership Theories (IFTs) remain a strong line of leadership research, while IFTs have infused a new perspective and excitement in our understanding of leadership and followership.
\end{abstract}

\section{Keywords}

Implicit Followership Theories, Followership, Leadership, Prototype

\section{Introduction}

Implicit Followership Theories (IFTs) are cognitive structures and schemas about the traits and behaviors that characterize followers. Leaders can further understand, explain and respond to followers' behaviors through IFTs (Weick, 1995). This study explores how leaders and employees interact with each other in the context of organizational leadership from the perspective of "leadership" and "employees". From 2013 to 2016, there were many articles about IFTs (Epitropaki et al., 2013; Junker \& van Dick, 2014; Xu, Li, \& Cao, 2015; Yang \& Peng, 2015). In addition, The Leadership Quarterly, a leading international journal on leadership and followership, launched a special journal about IFTs in 2014 (Foti et al., 2014). This shows that the academic community is very concerned about IFTs. In order to further understand and introduce IFTs, this paper will elaborate on the following three parts: the concept, structure and measurement, and related research.

Implicit Followership Theories (IFTs) are the practical application of cogni- 
tive theory in the research field of followership research, and are based on the development of Implicit Leadership Theories. Implicit Leadership Theories represent the formation of people's inner concept of leadership in a specific cultural context (Sternberg, 1985), and describe the cognitive structure of leaders' traits and abilities (Lord \& Maher, 1991). Implicit Followership Theories describe the cognitive structure of employees' characteristics and abilities. IFTs put the focus of the research perspective on the followers. IFTs are a kind of expectation of leaders to followers, which includes effective or positive characteristics related to followers (Van Gils et al., 2010). Carsten and Uhl-Bien (2009) define IFTs as the cognitive structure (schema) of the individual (a leader or follower) in the heart of an effective follower. The definition of Carsten and others emphasizes the validity of the followers, and does not contain all the followers in the reality, showing a certain parochial nature. Then Sy (2010) extends the concept of implicit followership theories. Sy defines it as cognitive structures and schemas about the traits and behaviors that characterize followers. Sy points out that Implicit Followership Theories not only include the leaders' assumptions about the characteristics and behavior of the followers, but also the employees' assumptions about their own traits and behavior. Sy does not distinguish the effectiveness of the followers in the definition of IFTs, so the prototype of "effective" and "invalid" followers is included. The extension of this concept is broader and has been supported by most researchers (Whiteley, Sy, \& Johnson, 2012). It is necessary to point out that implicit followership held by individuals is not the perception of the followership traits in reality. It is that individuals adopt their own social experience, in the organizational context by summing up the experience of interactive leader follower, and adopt continuous identification and internalization, and finally, followship prototype exists in the individual memory. According to the theory of social cognition, leaders' followship prototypes will affect the attitudes and behaviors of leaders and followers (Lord \& Maher, 1993). In their work, leaders will gradually choose, evaluate and treat employees based on their followship prototype. Huang (2008) points out the followship prototypes of leadership are mainly derived from the leaders' refining and summarizing the performance of the followers in their work. Leaders are more objective and sensitive to followers' characteristics. Most studies are from leaders' perspective to explore followers' followership characteristics and behaviors.

\section{Structures and Measures}

There are certain differences in the structure division of implicit followership. Scholars have divided the structure of implicit followership according to different research perspectives. Carsten et al. (2010) through qualitative interviews and summed up twelve follower traits, including loyalty, positive attitude, good communication, initiative, obey the arrangement, integrity, responsibility, flexibility, teamwork, expression of opinion, task consciousness and Work ownership. Carsten according to the individual differences in the twelve characteristics 
divides followers into passive, active and proactive. The submissive followers escape responsibility, love the passive acceptance of the leader's command and keep silent. Active followers can make appropriate suggestions, but eventually it will obey the leader's decision. Proactive followers can take their own responsibility and positive feedback and even challenge the leader's decision. This type of followers emphasized their influence on leadership. However, in general, the 12 traits that Carsten and others have summed up rarely include some of the negative traits of the followers. Then Sy (2010) developed a Implicit Followership Theories scale, with 18 topics, including trustworthiness, loyalty and rudeness. The questionnaire consists of two factors: positive prototype (followers should have traits) and negative prototype (followers should not have traits). Positive prototype includes three factors: industry, enthusiasm good citizen warmly. Negative prototype consists of three factors: conformity, incompetence and insubordinate. Sy further studies that leaders and followers have the same implicit followership structure, and the implicit schemas are basically the same. The discriminative validity and retest reliability of the questionnaire were good, and all reached the standard of psychometrics. Yip (2013), based on the combination of $\mathrm{XY}$ theory and attribution theory, puts forward that the structure of implicit followership can be divided into motivation and capability. The measurement tool is $\mathrm{Y}$ theory scale compiled by Kopelman et al., 2010. Tram-Quon (2013) divided the implicit followership into two categories: positive and negative, and measured the implicit followership by the two indirect methods of Implicit Association Test (IAT) and projective approach respectively. Derler and Weibler (2014) divide implicit followership up into trait dimension and behavior dimension. The structure of the trait dimension is the same as the positive prototype proposed by Sy, and the measurement also uses the part of the positive prototype in the scale. Behavioral dimension is divided into explorative activity and exploitative activity. The scale developed by Mom (2007) is measured.

\section{Research Status}

Implicit followership is a hot topic in recent years, and a new study has been carried out by scholars for implicit followership. In this study, we aim at following the existing empirical research and related theoretical models, and summarize and integrate the antecedents, outcome variables and theoretical foundations of implicit followership.

\subsection{Antecedents}

As the implicit followership of implicit nature, the discussion of the implicit followership "where to come" has attracted the attention of many scholars. By summarizing the previous studies, the antecedents of implicit followership include three aspects: environmental factors, individual factors and cultural differences. 


\subsubsection{Environmental Factor}

The construction of individual cognitive structure is the result of continuous interaction with the environment. The formation of implicit followership is more closely related to the family environment, the internal environment and the external environment. The family environment, such as early experience and parental rearing patterns, plays a key role in the construction of individual implicit cognition. Hunt et al. (1990) pointed out that individual early experience (irritant events) would affect the formation of implicit cognition in the individual. Parents are the earliest "leadership" in individual life, and parent-child interaction can be regarded as the earliest leading - following relationship. Keller (1999) studies show that the majority of individuals' expectations for intra-organizational roles, whether they are leaders or followers, are mostly the epitome of their parents' personality traits. In parent-child interaction, parents' satisfaction with their physical and psychological needs influences their future expectations of career socialization and interpersonal relationship. The individual's expectation, through the continuous development and internalization in the organizational situation, eventually exists in the individual cognitive system in an archetypal way. Parental rearing patterns also affect the formation of an individual followership prototype. Parental rearing patterns are authoritative and laissez faire individuals, and they are more likely to develop a negative, self appointed and selfish negative followership prototype. The type of democratic type of parenting style is more likely to develop a positive and positive followership prototype with a sense of cooperation, responsibility and active activity.

The influence of the internal environment on the individual followership prototype is mainly manifested in the organizational climate and the leadership style. The influence of organizational climate and parental rearing patterns on the formation of the individual followership prototype was similar. In the stress of authoritative leadership style or strict bureaucracy atmosphere, the prototype of individual formation is more passive and passive, which inhibits and even stifle individual initiative and creativity in this organization scenario (Blau, 1968). In a participatory leadership style or an authorized organizational climate, individuals are more likely to form active followership prototype. In this context, individuals can encourage and advocate individuals to actively participate in organizational decision making, and put forward their own opinions and suggestions (Srivastava et al., 2006). The study also showed that there was a significant difference between the transformational leadership and the transaction type leaders' expectations (Goodwin et al., 2000). The influence of the external environment on the individual followership prototype is mainly reflected in the following aspects: when the organization is in the turbulent external environment of market supply and demand, leaders prefer the followers with good citizenship traits and exploratory innovative behaviors. When the organization is in a fiercely competitive external environment, though leaders do not particularly prefer some followership prototype, there is a significant positive correlation 
between market competition and the good citizenship dimension of individual followership prototype three dimensions.

\subsubsection{Individual Factors}

The physiological and psychological factors of the individual have an important influence on the formation of the implicit followership prototype. The effects of physiological factors are mainly manifested in gender, age, education level and so on. Previous studies have shown that there are significant gender differences in the dimension of good citizens. In the Sy (2010) study, the male leader score was higher than the female leader in the disobedience and enthusiasm dimension of the implicit following prototype. In the score of implicit followership negative prototype, the score of young leaders is higher than the older leader. In the score of implicit followership positive prototype, leaders with higher education level are higher than those with relatively low education. The influence of psychological factors is mainly manifested in emotion, personality, values and so on. Kruse (2011) explored the effect of individual emotion on implicit followership through four experimental designs. The results showed that when the negative emotions (such as sadness and anger) were activated, the subjects' implicit followership prototypes scores were significantly higher than those of the heartless ones. When the cheerful mood of the subjects was activated, the scores of the subjects' implicit followership positive prototype were significantly higher than those in the unmerciless group. It is worth noting that the implicit followership prototype of emotion in the individual has a starting effect, but this change is temporary. The study did not confirm that emotions can alter the implicit followership prototype structure of an individual. Previous studies have shown that personality is a source of variation in individual cognitive patterns. Epitropaki et al. (2013) pointed out that extraversion in the big five personality is the key factor to predict the implicit followership prototype, which helps individuals construct active (positive) implicit followership prototypes. Values will affect the individual's cognitive behavior pattern, so that values may affect the implicit followership prototype construction of the individual.

\subsubsection{Cultural Difference}

The construction of the implicit followership prototype of the individual comes from the development of childhood. Cultural difference is the macro environment of individual growth, and it will influence the construction of individual implicit followership prototype under the specific cultural background. There are obvious differences between the eastern countries and the western countries in the understanding of implicit followership. The eastern countries believe that excellent followers should have the qualities of respect for authority, devotion and loyalty. Hoption et al. (2012) pointed out that respect for authority and obedience to authority in western culture is regarded as a characteristic of negative following archetype. Holzinger et al. (2006) the cross-cultural study shows that the cultural differences in the country will affect the construction of the individ- 
ual implicit followership prototype.

\subsection{Outcomes}

This study will sort out the outcomes variables from leaders' and followers' implicit followership prototype to their attitudes, behaviors and their followers or leaders' influence.

\subsubsection{Leaders' Implicit Followership Prototype}

A leaders' implicit followership prototype will affect the leader's management mode, leader-member exchange (LMX), leader's affection for employees and performance expectation. The leaders themselves have their own assumptions about the followers, which will affect the way leaders take the management of their subordinates (Mcgregor, 2017). The research of Duong (2011) and others shows that the positive followership prototype of the leader can promote the leader's transformational leadership. Yit (2013) studies also show that leaders positive followership prototype to promote leadership behavior. Leader followership prototype is positively related to leaders' LMX, and positively related to love degree of followers and performance expectation. It is worth noting that Kedharnath (2011)'s research results indicate that leaders' followership prototypes have no significant influence on leader-member exchange relationship.

Leaders' implicit followership prototype will affect the followers' preference for leaders, followers' leader-member exchange (LMX) and followers' work performance, job satisfaction, role behavior and organizational commitment, and organizational citizenship behavior. The study of Sy (2010) showed that the leader's positive implicit followership prototype was positively correlated with the degree of the followers' preference for the leaders. The leader's positive implicit followership prototype has a significant positive correlation with the leader-member exchange (LMX) evaluated by the followers. The leader's positive implicit followership prototype has a significant positive correlation with the job satisfaction of the followers. Whiteley (2012) verified the leaders' implicit followership prototype has the positive effect on job performance, and has Pygmalion Effect explained this effect. The positive influence of leaders' implicit followership prototype on subordinates' performance is mainly through the leader's performance expectation, love and leader subordinate exchange relationship. Duong (2011) and others, through the study of leading-subordinates, concluded that the positive implicit followership prototype of the leader would significantly affect the organizational citizenship behavior of the subordinates.

\subsubsection{Followers' Implicit Followership Prototype}

The followers' implicit followership prototypes lead to different attitudes and behaviors of subordinates, and show their followers' characteristics in the actual organization work (Lord et al., 1984). The followers' implicit followership prototype determines his following behavior, so the implicit followership prototype of the followers in the organization will affect the individual's following traits. 
When the organization develops in a relatively stable stage, passive followers will choose the status quo of the follower mode. But if the organization development is in rapid change and challenging period, is more accepting initiative, positive suggestions of followers, these followers of the courage to dare to challenge and question the leader's decision, greatly improving the effectiveness of organization and leadership activities.

Carsten et al. (2010) systematically discussed the influence of the implicit followership prototype on the attitude and behavior of the followers in the organization. Carsten et al. (2010) followed the interview method to divide the implicit followership prototype of followers into three categories: proactive, active and passive. Carsten et al. points out that the type of implicit followership prototype held by the followers determines their following traits. The followers who hold the proactive type implicit followership prototype, they are active in their work, dare to bear the responsibility, and have the responsibility. Active followers will emphasize their influence on leaders through positive feedback on leaders' decisions, or even challenge leaders' decisions, and regard themselves as leaders. The followers of the active followership prototype will choose the right time to give positive advice to leaders, and offer their initiative, but this proposal is not a challenge leader, this type of followers will obey all decisions made by leaders. The followers who followership prototype passively, they prefer to be directed by a leader. There are few proactive behaviors such as advice. They like to passively accept the instructions issued by leaders. They often act as evasion of responsibilities and silence in their work. Previous studies have mainly discussed the influence of following prototype on employees' work behavior and well-being, and few studies will follow implicit prototypes and explore the internal mechanism and mitigation methods of this negative impact.

\section{Summary and Conclusion}

Implicit Followership Theories (IFTs) are the cognitive structures and schemas about the traits and behaviors that characterize followers. Our review has highlighted the positive contributions that socio-cognitive approaches have made to understanding followership. The research of IFTs not only makes up for the lack of research on the cognitive process of leaders during the leadership process, but also has important implications for management practices. Leaders and followers each have their own schema for followers (Sy, 2010). For followers, understanding the differences between leaders' IFTs and their own IFTs can be used to adjust their behavior and improve their relationship with leaders. For leaders, they should understand their IFTs and followers' IFTs. Different one can be targeted to change the management approach, adjust their own or followers of IFTs to improve management efficiency. We reviewed both direct and indirect measures and also synthesized current research. Together, these results demonstrate that IFTs have significant practical implications for leaders, followers and workplace outcomes. We accordingly provided perspectives on practical inter- 
ventions for using IFTs for the development of leaders and followers. In sum, Implicit Followership Theories (IFTs) remain a strong line of leadership research, while IFTs shall infuse a new perspective and excitement in our understanding of leadership and followership. As IFTs are a relatively new concept, the current research on IFTs is in its infancy and there are many issues that need to be explored in the future. We believe that it may be valuable to strengthen the following directions in future research.

First, strengthen the inspection and development of measurement tools. Although IFTs are still a relatively new concept, as mentioned above, some researchers have begun to try to measure them. This is a gratifying start, but there are still some issues that need further follow-up. Although the overall reliability and validity of some measurement tools (such as the direct measurement tool developed by Sy for IFTs) has been basically supported in some studies, for some structures and contents, the views of different researchers are not consistent and need further study.

Second, enrich research on the factors that influence the IFTs or the antecedents. It is generally believed that the individual's implicit theory is formed and developed during the early socialization of the individual. Therefore, most people regard IFTs as a matter of course (Epitropaki et al., 2013) and ignore the factors affecting them. How are IFTs formed? What factors influence the changes in individual IFTs? How do individual IFTs change as individuals grow? These are still issues of exploration value.

Third, the influence of followership prototype to leaders and followers. Followship prototype impacts on leaders. The existing research conducted a preliminary exploration of the relationship between prototypes and transformational leadership and improper supervision, and believes that leaders' followship prototypes have an important guiding role in leadership behavior. Based on the above perspectives, future research can further explore the influence of leaders' followship prototypes on some leadership types or leadership styles related to transformational leadership, such as true leadership, moral leadership, and benevolent leadership. These leadership styles share common features. It is about caring, trusting and supporting followers and is committed to providing good conditions and environment for followers to achieve common goals.

\section{References}

Blau, P. M. (1968). The Hierarchy of Authority in Organizations. American Journal of Sociology, 73, 453-764.

Carsten, M. K., \& Uhl-Bien, M. (2009). Implicit Followership Theories (IFT): Developing and Validating an IFT Scale for the Study of Followership. In Annual Meeting of the Southern Management Association. Ashville, NC.

Carsten, M. K., Uhl-Bien, M., West, B. J., Patera, J. L., \& McGregor, R. (2010). Exploring Social Constructions of Followership: A Qualitative Study. The Leadership Quarterly, 21, 543-562. https://doi.org/10.1016/j.leaqua.2010.03.015

Derler, A., \& Weibler, J. (2014). The Ideal Employee: Context and Leaders' Implicit Fol- 
lower Theories. Leadership \& Organization Development Journal, 35, 386-409. https://doi.org/10.1108/LODJ-12-2012-0158

Duong, J. (2011). Leaders' Conceptions and Evaluations of Followers as Antecedents of Leadership Style, Leader-Member Exchange and Employee Outcomes. Doctoral Dissertation, Los Angeles, CA: Alliant International University, Marshall Goldsmith School of Management.

Epitropaki, O., Sy, T., Martin, R., Tram-Quon, S., \& Topakas, A. (2013). Implicit Leadership and Followership Theories "In the Wild": Taking Stock of Information-Processing Approaches to Leadership and Followership in Organizational Settings. The Leadership Quarterly, 24, 858-881. https://doi.org/10.1016/j.leaqua.2013.10.005

Foti, R., Hansbrough, T. K., Epitropaki, O., \& Coyle, P. (2014). Special Issue: Dynamic Viewpoints on Implicit Leadership and Followership Theories. Leadership Quarterly, 25, 411-412. https://doi.org/10.1016/j.leaqua.2014.02.004

Goodwin, V. L., Wofford, J. C., \& Boyd, N. G. (2000). A Laboratory Experiment Testing the Antecedents of Leader Cognitions. Journal of Organizational Behavior, 21, 769-788.

Hoption, C., Christie, A., \& Barling, J. (2012). Submitting to the Follower Label. Zeitschrift für Psychologie, 220, 221-230. https://doi.org/10.1027/2151-2604/a000116

Huang, X., Wright, R. P., Chiu, W. C., \& Wang, C. (2008). Relational Schemas as Sources of Evaluation and Misevaluation of Leader-Member Exchanges: Some Initial Evidence. The Leadership Quarterly, 19, 266-282. https://doi.org/10.1016/j.leaqua.2008.03.003

Junker, N. M., \& van Dick, R. (2014). Implicit Theories in Organizational Settings: A Systematic Review and Research Agenda of Implicit Leadership and Followership Theories. The Leadership Quarterly, 25, 1154-1173. https://doi.org/10.1016/j.leaqua.2014.09.002

Kedharnath, U. (2011). The Influence of Leaders' Implicit Followership Theories on Employee Outcomes. Fort Collins, CO: Colorado State University.

Kopelman, R. E., Prottas, D. J., \& Falk, D. W. (2010). Construct Validation of a Theory X/Y Behavior Scale. Leadership \& Organization Development Journal, 31, 120-135. https://doi.org/10.1108/01437731011024385

Lord, R. G., \& Maher, K. J. (1991). Leadership and Information Processing:, Linking Perceptions and Performance. Academy of Management Review, 18, 153.

Lord, R. G., \& Maher, K. J. (1993). Leadership and Information Processing: Linking Perceptions and Performance. Academy of Management Review, 18, 153-156.

Lord, R. G., Foti, R. J., \& De Vader, C. L. (1984). A Test of Leadership Categorization Theory: Internal Structure, Information Processing, and Leadership Perception. Organizational Behavior and Human Performance, 34, 343-378. https://doi.org/10.1016/0030-5073(84)90043-6

Mcgregor, D. (2017). The Human Side of Enterprise. Reflections the Sol Journal, 2, 6-15.

Srivastava, A., Bartol, K. M., \& Locke, E. A. (2006). Empowering Leadership in Management Teams: Effects on Knowledge Sharing, Efficacy, and Performance. Academy of Management Journal, 49, 1239-1251.

Sternberg, R. J. (1985). Implicit Theories of Intelligence, Creativity, and Wisdom. Journal of Personality \& Social Psychology, 49, 607-627. https://doi.org/10.1037/0022-3514.49.3.607

Sy, T. (2010). What Do You Think of Followers? Examining the Content, Structure, and Consequences of Implicit Followership Theories. Organizational Behavior and Human Decision Processes, 113, 73-84. https://doi.org/10.1016/j.obhdp.2010.06.001

Van Gils, S., Van Quaquebeke, N., \& Van Knippenberg, D. (2010). The X-Factor: On the 
Relevance of Implicit Leadership and Followership Theories for Leader-Member Exchange Agreement. European Journal of Work and Organizational Psychology, 19, 333-363. https://doi.org/10.1080/13594320902978458

Weick, K. E. (1995). Sensemaking in Organizations. Academy of Management Review, 21, 1226.

Whiteley, P., Sy, T., \& Johnson, S. K. (2012). Leaders' Conceptions of Followers: Implications for Naturally Occurring Pygmalion Effects. Leadership Quarterly, 23, 822-834. https://doi.org/10.1016/j.leaqua.2012.03.006

Xu, S., Li, Y., \& Cao, Y. (2015). The Influence of Individual Personality Traits on Followership Behavior: A Construction of Modulating Meditation Model. Human Resources Development of China, 23, 280-288.

Yang, H., \& Peng, J. (2015). A Literature Review of Implicit Followership Theory. Foreign Economics \&Management, 37, 16-26.

Yip, J. (2013). How Implicit Assumptions about Followers Shape the Mentoring Behaviors of Top Executives. Academy of Management Proceedings, 2013, 11572. 